\title{
FORMAÇÃO CONTINUADA DE PROFESSORES QUANTO ÀS TEMÁTICAS MUNDO DO TRABALHO E PERSPECTIVA DE VIDA
}

\author{
Aléx Gomes da Silva ${ }^{1}$, Raquel Rosan Christino Gitahy ${ }^{2}$ \\ Universidade do Oeste Paulista - UNOESTE. ${ }^{1}$ Mestre em Educação. ${ }^{2}$ Docente do Programa de Pós-Graduação em \\ Educação, Presidente Prudente -SP. E-mail: silvaalgo@yahoo.com.br
}

\begin{abstract}
RESUMO
O objetivo deste artigo é analisar as contribuições do Programa Educacional de Atenção ao Jovem (Peas Juventude) na formação continuada de professores, propiciando a aproximação dos docentes a temas relacionados ao Mundo do Trabalho e Perspectiva de Vida, discutindo empreendedorismo, protagonismo, relações interpessoais, habilidades e aptidões, sonhos e desejos, crescimento pessoal e profissional. A pesquisa valeu-se de uma abordagem qualitativa, com o estudo de caso, contando com a participação de oito docentes e o coordenador do projeto. Os dados obtidos, por meio de observação, questionários e entrevista semiestruturada, apontaram a satisfação dos membros em integrar o projeto Peas Juventude, tendo uma formação continuada em serviço, com interferências diretas e positivas no ambiente escolar.
\end{abstract}

Palavras-chave: Formação Continuada; Professores; Projeto Peas Juventude.

\section{TEACHERS' CONTINUED EDUCATION PROVIDED BY THE EDUCATIONAL PROGRAM TO PROVIDE CARE FOR YOUTH - PEAS JUVENTUDE - ON THE ISSUE WORLD OF LABOR AND PERSPECTIVE ON LIFE}

\begin{abstract}
This paper was carried out to analyze the contributions made by the Educational Program to Provide Care for Youth (Peas Juventude) to further teachers' continued education, the broaching both by teachers and youth of issues related to the World of Labor and Perspective on Life, discussing entrepreneurship, interpersonal relations, skills and competence, dreams and wishes, personal and professional growth. It is a continued education in work, with direct and positive interference in their school environment.
\end{abstract}

Keywords: Continued education; Teachers; Peas Juventude Project. 


\section{INTRODUÇÃO}

Os cursos e projetos que objetivam oferecer formação continuada a professores, em várias modalidades de ensino, vêm passando por intensas transformações de natureza estrutural e pedagógica.

Num cenário recente, os educadores estão presenciando possibilidades de formação continuada cada vez mais integradas com as escolas, permitindo que se processe uma capacitação em serviço, garantindo acessibilidade e permanência a um maior número de profissionais.

Uma vertente no segmento desses cursos é a associação entre encontros presenciais e instrução on-line, por meio de ambientes virtuais de aprendizado.

Pensar na formação continuada de professores é refletir sobre a prática docente diante dos desafios educacionais que se impõem. É buscar melhorias, alternativas e soluções para problemáticas em diversos contextos.

Biaggi (2007, p. 99) conceitua

formação continuada como:

[...] processos que envolvem a atualização teórica na área que o professor ensina, que se realizam através de cursos, palestras, participação em eventos, como também os processos organizados por iniciativa das próprias escolas, de acordo com as necessidades específicas dos que nela atuam e por elas identificadas.

O mesmo autor atribui à constante evolução dos métodos e teorias e à velocidade com que essas mudanças ocorrem como elementos impulsionadores da formação continuada no âmbito escolar.

“Os profissionais da educação têm buscado formas de atualização e informação para responder às necessidades que são colocadas hoje pela dinâmica do trabalho pedagógico". (BIAGGI, 2007, p. 101).

Isso é um aspecto também evidenciado por Hypollito (1999, p. 58) em seu artigo Repensando a Formação Continuada:

Mesmo supondo que o professor tenha recebido adequada formação, a atualização é uma exigência da modernidade. Tabus caem, métodos são questionados, conceitos são substituídos, o mundo da ciência, do trabalho, da política, da empresa caminha velozmente para mudanças de padrões e exigências.

Recorrendo à visão de Nóvoa (2002, p. 59) sobre essa temática concorda-se que:

[...] falar de formação contínua é falar de uma autonomia contextualizada da profissão docente. Importa valorizar paradigmas de formação, a preparação de professores 
reflexivos, que assumam a responsabilidade do seu próprio desenvolvimento profissional e que participem como protagonistas no desenvolvimento das políticas educativas.

Aliás, o aspecto do protagonismo é a bandeira levantada pelo Programa Educacional de Atenção ao Jovem - Peas Juventude, como filosofia em suas ações.

Portanto, buscou-se analisar as contribuições do referido projeto para a formação continuada de professores, propiciando a aproximação dos docentes a temas relacionados ao Mundo do Trabalho e Perspectiva de Vida.

\section{METODOLOGIA}

O presente trabalho, após ter sido avaliado e aprovado pelo Comitê de Ética em Pesquisa (CEP), valeu-se de uma abordagem qualitativa, empregando como procedimento o estudo de caso.

Os estudos qualitativos podem descrever a complexidade de determinado problema e a interação de certas variáveis, compreender e classificar os processos dinâmicos vividos por grupos sociais, contribuir no processo de mudança de dado grupo e possibilitar, em maior nível de profundidade, $\quad \mathrm{O}$ entendimento das particularidades

do comportamento dos indivíduos. (DIEHL; TATIM, 2004, p. 52)

Para o desenvolvimento da pesquisa contou-se com a participação de oito docentes, além do coordenador do Peas, e recorreu-se aos seguintes instrumentos de pesquisa: consulta bibliográfica e documental, aplicação de questionários, realização de entrevista semiestruturada e análise de um blog.

\section{O Cenário da Pesquisa e o Projeto Peas}

\section{Juventude}

O cenário da pesquisa é uma instituição de ensino, localizada no interior de Minas Gerais, que participa desde 2008 do Projeto Peas Juventude.

$$
\text { Proposto e coordenado pela }
$$
Secretaria de Estado da Educação de Minas Gerais, por meio da Subsecretaria de Desenvolvimento da Educação Básica e da Superintendência do Ensino Médio, o Peas surgiu com o intuito de renovar os ideais de jovens e adolescentes, incentivando-os a atuarem de forma intensa e consciente no cenário social, promovendo o protagonismo juvenil e refletindo a sua realidade, por meio de atividades culturais, debates, oficinas, ações de mobilização e de integração dos jovens ao mercado de trabalho. 
Na composição do Peas, encontra-se a atuação de dois grupos que se constituem para o desenvolvimento de um trabalho coletivo: um formado pelos JPPeas (Jovens Protagonistas do Peas) e, o outro, pelos GDPeas (Grupo de Desenvolvimento Profissional do Peas). Dessa forma:

[...] o trabalho em conjunto busca favorecer a socialização de conhecimentos, a democratização das relações, a quebra de estereótipos e hierarquias e a construção de parcerias efetivas entre adultos $\mathrm{e}$ jovens, professores e alunos. (MINAS GERAIS, 2009, p. 41).

O GDPeas tem uma composição diferenciada, por permitir que profissionais de diversas áreas do saber estejam envolvidos no planejamento e na execução das oficinas com os JPPeas, buscando:
[...] favorecer a educação integrada do sentir, do pensar e do agir, bem como o desenvolvimento da competência dos participantes de monitorar a própria aprendizagem. Dentro dessa perspectiva, a metodologia se define como vivencial, dialógica, reflexiva, metacognitiva $e$ pró-ativa. (MINAS GERAIS, 2009, p. 53, grifos do autor).

Para divulgar suas ações, um conjunto de blogs é empregado, em que cada instituição estadual de ensino apresenta e organiza seu blog, ao integrar o projeto.

\section{Apresentação e Análise dos Dados}

Com o propósito de preservar a identidade dos professores e do coordenador pedagógico adotou-se códigos, com letras e números, para a identificação dos mesmos, como apresentado no Quadro 1.

Quadro 1. Identificação dos sujeitos da pesquisa

Fonte: $\mathrm{O}$ autor

\begin{tabular}{|l|l|l|l|l|l|l|l|l|l|}
\hline $\begin{array}{l}\text { Sujeitos da } \\
\text { Pesquisa }\end{array}$ & $\begin{array}{l}\text { Coordenador do } \\
\text { Projeto }\end{array}$ & \multicolumn{6}{|l|}{ Professores Pesquisados } \\
\hline Códigos & COP & P1 & P2 & P3 & P4 & P5 & P6 & P7 & P8 \\
\hline
\end{tabular}

Os dados coletados permitiram definir o perfil de alguns professores que integram o Projeto Peas, mediante informações a respeito de sua formação profissional.
Os sujeitos da pesquisa são, em sua maioria, do sexo feminino, confirmando as estatísticas de predominância das mulheres no exercício do magistério. 
Quanto à formação, todos os docentes possuem curso de pós-graduação lato sensu e ao serem interrogados sobre o tempo de serviço na rede estadual de ensino, $62,5 \%$ dos participantes informaram ter, em média, 15 anos ou mais.

\section{A Formação Continuada de Professores} promovida pelo Projeto Peas Juventude

A equipe GDPeas recebe as informações através do coordenador do projeto na escola, que é o agente multiplicador, definindo as estratégias (em parceria com o grupo) que garantem a continuidade das oficinas e capacitações.

O vínculo com o grupo oferece aos docentes a oportunidade de formação continuada e maior aproximação com os alunos que se consolida com a convivência e a cumplicidade.

Os professores pesquisados P5 e P8 relataram como se davam os encontros entre os docentes do grupo GDPeas:

Em nossas reuniões, discutimos vários temas interessantes e planejamos como serão os encontros com os alunos do Peas, definindo as ações a serem realizadas, as dinâmicas, os vídeos e atividades presentes nos roteiros de estudos, que serão socializadas com o grupo. $(P$ 8)

Temos encontros a cada 15 dias, em média. Lemos o material que a coordenação nos passa, discutimos $e$ planejamos o que será repassado aos alunos. É um aprendizado coletivo em que um ajuda o outro $e$ compartilha o que sabe. ( $P$ 5).

Sobre o aspecto da formação, verificase que:
A Proposta de Formação do Peas Juventude não se confunde com um simples treinamento, nem se restringe a oferecer opções de cursos de capacitação. Se assim fosse, ele não estaria acrescentando qualquer novidade ao que já se faz. (MINAS GERAIS, 2009, p. 48).

Em consulta ao blog, constata-se um total de 86 posts para o ano de 2009 , sendo que, destes, 41 tratavam da formação inicial e continuada, o que representa $48 \%$ do total de postagens.

A formação inicial compreende uma capacitação que inclui 24 horas. É voltada apenas para o GDPeas e visa permitir a apropriação das diretrizes do projeto, bem como o conhecimento da temática e a divulgação das ações a serem desempenhadas.

A Formação Inicial dá-se de forma presencial, ocorre para o coordenador de GDPeas na ocasião do 1응 Encontro e é replicada pelo coordenador para o seu 
grupo, no âmbito da escola, entre os meses de fevereiro e março. $O$ material pedagógico de apoio, constituído pelos Tutoriais, Diretrizes, Manuais e Guias de Formação I e II, que contemplam as lâminas em Power Point, são entregues na versão impressa para o coordenador de GDPeas na ocasião da sua formação e em versão eletrônica disponibilizado no blog da coordenação central. (MINAS GERAIS, 2011, p. 8).

O excerto de no 1 traz a impressão da equipe integrante do projeto sobre a formação inicial:

\section{Excerto no 1 - Retirado do Blog Peas}

\section{$19 / 04 / 2009$}

A Formação Inicial proporcionou a sensibilização e o aprofundamento da filosofia da proposta até 2010. Houve uma conscientização da importância do projeto na Escola e de todos estarem inteirados do assunto. Desse modo e com o apoio da direção escolar para a realização do evento da Formação Inicial, o convite para sua participação foi amplamente aceito, resultando em participação significativa na escola.

Por intermédio do blog, os roteiros de estudos são postados pelos orientadores titulares e assistentes, apresentando "[...] textos de apoio da área temática e roteiros dirigidos de estudos e tarefas para serem executados pelos GDPeas" (MINAS GERAIS, 2011, p. 8).

Nos roteiros de estudos têm-se à disposição do grupo participante, textos, sugestões de dinâmicas, vídeos e músicas, entre outras seções, que permitem à equipe GDPeas planejar e desenvolver as reuniões de forma segura, participativa e descontraída, motivando os jovens a refletirem sobre os temas em pauta. Constitui, dessa forma, um material essencial na formação docente.
Um dos professores confirmou isso em seu depoimento:

Em cada roteiro que recebemos, temos dinâmicas interessantes, textos bem selecionados $e$ motivadores, existem sugestões de vídeos, sites, livros e outros materiais apropriados para o trabalho com os jovens. (P 2)

Para o coordenador do projeto Peas:

Os roteiros de estudos de formação continuada complementam, estruturam, preenchem e direcionam as lacunas existentes entre as ações planejadas e oficinas praticadas, não só com suporte de conteúdo, mas e principalmente

com 
estratégias inteligentes, atrativas e praticáveis. Este suporte não pode deixar de existir. (COP)

A sequência dos roteiros de estudos (num total de 5) integra a formação continuada definida no Projeto Peas, com 54 horas de formação para os membros do GDPeas e contemplando 40 horas para os JPPeas. "A Formação Continuada tem atividades presenciais, por meio dos encontros e à distância, pelo blog e correio web". (MINAS GERAIS, 2011, p. 8).

Para Imbernón (2004, p. 52), a formação continuada "[...] deve propor um processo que dote $\mathrm{o}$ professor de conhecimentos, habilidades e atitudes para criar profissionais reflexivos ou investigadores".

Nesse sentido, o coordenador do Peas avalia que:

Os conhecimentos contidos nos roteiros têm um grande potencial de oportunizar outras reflexões e trabalhos pedagógicos engajados a esses temas, já que a adolescência e a construção de valores sociais deve ser uma constante preocupação em nossa ação docente. (COP)

Interrogados sobre a importância da formação promovida pelo Peas Juventude, alguns docentes destacaram:
Considero muito importante, pois estamos aprofundando nossos conhecimentos em temas como empreendedorismo, protagonismo, perspectiva de vida, entre outros tantos temas ligados à juventude $e$ seus anseios. (P 3)

Extremamente importante, pois passamos por uma capacitação valiosa nas temáticas Mundo do Trabalho e Perspectiva de Vida, o que reflete em nossa prática educativa com os jovens. (P 7)

A capacitação do Peas ocorre na escola e isso favorece uma maior participação dos professores. (P10)

É uma capacitação diferente, já que estamos refletindo temas de interesse dos jovens e, como educadores, precisamos estar envolvidos nesses assuntos, ajudando-os em suas escolhas profissionais $e$ a ter atitudes empreendedoras. (P 1)

Constata-se que a formação continuada de professores inserida no Projeto Peas Juventude foi bem aceita pelos envolvidos, pelo comprometimento no planejamento e execução das ações, bem como através da avaliação que o grupo fez deste período (excerto no 2): 
Excerto no 2 - Retirado do Blog Peas

$15 / 07 / 2009$

Constituímos uma equipe sintonizada com o "Mundo do Trabalho", com o empreendedorismo, e o que isto pode promover de crescimento, de perspectivas, de superação e persistência, estimulando sonhos e apontando caminhos para realizá-los.

Como foi valiosa a troca de experiências entre professores e alunos, compartilhando muito mais que informações, e sim, ideais, projetos, desejos de mudança e de uma sociedade melhor, transformada pelo poder da educação.

Em cada etapa dos Roteiros de Estudos, nas dinâmicas de grupo e nas apresentações ficou evidente o compromisso de nossos alunos com o Peas Juventude e, nós, educadores, orgulhosos deles fazerem parte dessa equipe, que será disseminadora do projeto para a escola e comunidade.

\section{CONSIDERAÇÕES FINAIS}

A formação continuada de professores possibilita uma renovação, que é percebida no ambiente educacional pela mudança no agir e no pensar, repercutindo na prática pedagógica desses profissionais.

“A formação contínua pode constituir um importante espaço de ruptura, estimulando o desenvolvimento profissional dos professores" (NÓVOA, 2002, p. 59).

Quanto ao aspecto da formação ocorrer no âmbito escolar, isso é extremamente positivo, visto que, segundo Almeida (2005, p. 13):

[...] a formação contínua desenvolvida no interior da escola se constitui num movimento colaborativo, que precisa ser sustentado por um projeto formulado claramente por todos os envolvidos e ser orientado pelo gosto por aprender, cultivado carinhosamente no trabalho escolar, o que vale para professores e alunos.

Concorda-se com a percepção de Gatti (2003, p. 203), ao afirmar que:

[...] para que mudanças em concepções e práticas educacionais de professores ocorram, é necessário que os programas que visam a inovações educacionais, aperfeiçoamentos, atualizações tenham um entrelaçamento concreto com a ambiência psicossocial em que esses profissionais trabalham e vivem.

E este aspecto, em particular, tem sido considerado pelo Projeto Peas Juventude, colocando os docentes em contato com temas relevantes, cuja discussão aborda, entre outros assuntos, o 
protagonismo juvenil e o impacto do empreendedorismo e do cooperativismo na sociedade atual.

\section{REFERÊNCIAS}

ALMEIDA, M. I. Formação contínua de professores em face das múltiplas possibilidades e dos inúmeros parceiros existentes hoje. 2005. Disponível em: <http://www.tvbrasil.org.br/fotos/salto/serie s/150934FormacaoCProf.pdf >. Acesso em: 20 ago. 2012.

BIAGGI, A. F. Formação continuada de professores: concepções e práticas. Comunicações. Revista do Programa de PósGraduação em Educação da UNIMEP.

Piracicaba, ano 14, n. 1, p. 99-115, jun. 2007.

DIEHL, A. A.; TATIM, D. C. Pesquisa em ciências sociais aplicadas: métodos e técnicas. São Paulo: Prentice Hall, 2004.

GATTI, B. A. Formação continuada de professores: a questão psicossocial. Cadernos de Pesquisa, n. 119, p. 191-204, jul. 2003.

HYPOLITTO, D. Repensando a formação continuada. Integração: ensino, pesquisa e extensão, São Paulo, ano V, n. 16, p. 56-59. fev. 1999.

IMBERNÓN, F. Formação docente e profissional: formar-se para a mudança e a incerteza. 4. ed. São Paulo: Cortez, 2004. MINAS GERAIS (Estado). O Programa Educacional de Atenção ao Jovem - Peas Juventude. Disponível em: <http://200.198.28.154/sistema44/PROJETO S/

TRANSFER/SEMP/Medio/conteudo/PEAS/Da dos\%20Peas.pdf>. Acesso em: 10 out. 2011.

MINAS GERAIS (Estado). Secretaria de Estado da Educação. Guia de formação inicial Parte I. Belo Horizonte, 2009.
NÓVOA, A. Formação de professores e trabalho pedagógico. Lisboa: Educa, 2002.

Recebido para publicação em 18/08/2014 Revisado em 29/08/2014

Aceito em 01/09/2014 